\title{
Revaluation of the Local Product, a Good Opportunity for the Rural Development in Albania
}

\author{
Prof. Edlira Llazo Ph. D \\ University "Aleksander Moisiu" Durres, Albania \\ Ilazo@hotmail. it
}

\begin{abstract}
Even though agriculture is one of the most important sectors in the Albanian economy, which has employed $40 \%$ of the labor force, after the fall of communism has been faced with the phenomenon of abandonment, with a poor development and is nowadays in search of developing alternatives. New developing alternatives that use the competing advantages of the sector of agriculture in Albania can be discovered by analysing the characteristics of this sector and confronting them with new developments of the sector in Europe. For this purpose within this study is made a questionnaire with the farmers to notice their key concerns in their work and to understand their readiness to be part of innovative schemes that will revalue the local product and will approach them to the consumer.
\end{abstract}

Keywords : local product, farmers, innovative schemes

\section{Introduction}

In the last two decades in Albania has occurred a huge economical transformation. Since 2000, it has had an economic growth by $7 \%$, whereas agricultural sector has marked in the same period of time growth by $3-3,5 \%$. This digit is enough to understand that this important sector of the Albanian economy hasn't followed the same steps as the national economy. Agriculture, is one of the most important sectors in income growth, improvement of the trade balance, but most of all in the recovery of the population in these particular areas. This sector is experiencing a long and slow transition to pass from the level of fulfilling the needs towards a commercial sector. After the crisis in the beginning of the ' 90 , agriculture passed a transformation process from collective farms to the free market economy. But, as the other parts of economy faced drastic structural changes, the barriers of the agricultural sector made the development continuously hard. The slowdown of the sector is shown by its contribution in GDP from $35 \%$ in 1995 goes down to $20 \%$ in 2012 . All this panorama, raises a concern about the way and the guiding of development of this sector in the new conditions of:

The need of growth of the agricultural and livestock production and growth of reproductive ability,

Actual problems of agriculture in conditions of the process of integration Albania in EU and its integration in the European market etc.

Continuous growth of demand for standards as conditions for EU integration,

Economical crisis that has put at risk European economy.

In these conditions, the need of new approach of the sector focusing on the market and the agricultural marketing, would help to adapt the politics and the intervention in the sector towards a bigger efficiency. The identification and the promotion of the advantages would make a competitive agricultural product in the market. A serious approach to agricultural marketing, as a process in the value chain, in the transition of the product from the farm to the consumer would help the farmer to come out of its actual situation.

\section{Literature Review}


Local Food Systems:

A local food system is one in which foods are produced, processed and retailed within a defined geographical area. Examples of local food systems are: farmers markets, farm gate sales, vegetable box delivery schemes, community supported agriculture and public procurement schemes which source food from within a defined geographical radius. The foods which are exchanged within local food systems are usually those which are traceable to a particular place of origin, and have distinctive qualities or characteristics. They are often unprocessed or lightly processed foods. There is as yet no legally agreed definition of local food, nor of the geographical scale of the 'local'. The local is always experienced and understood in relation to larger geographical scales, such as the regional, national or global. The question of where the local area ends and another scale begins is subjective, depending on context (density of populations, accessibility and rural or urban character for example) and purpose.

The complex nature of contemporary food systems, even for seemingly simple food commodities, also makes it difficult to define 'local' food. For example, unless otherwise specified, locally bred chickens may well have been raised on feed sourced from thousands of miles away. For processed products consisting of a variety of ingredients, the situation is still more complex. Products may be grown or reared in one location, moved to another for processing and packaging, and then returned to the original location for sale. So they may be considered 'local' foods in the sense that they have been produced and consumed locally, but might have generated several hundred food miles during the stages in

between. Dishonest traders can take advantage of this to tap into consumer interest in local foods (Local Government Regulation 2011).

\section{Short Food Supply Chains:}

The definition of short food supply chains developed by Marsden et al. (2000) is referenced by many subsequent researchers. They argue that SFSCs have capacity to 'resocialize' or 're-spatialize' food, thus allowing consumers to make value-judgements about foods. The foods involved are defined by the locality or even specific farm where they are produced. Interestingly, Marsden et al. (2000: 426) make clear that "it is not the number of times a product is handled or the distance over which it is ultimately transported which is necessarily critical, but the fact that the product reaches the consumer embedded with information. "What they mean by 'embedded' with information is for example printed on packaging or communicated in person at the point of sale.

This information "enables the consumer to confidently make connections and associations with the place/space of production, and potentially the values of the people involved and the production methods employed" (2000: 425, their emphasis). The differentiation of products in this way, in theory, allows products to command a premium price, if the information provided to consumers is considered valuable.

An important principle of SFSCs is that the "more embedded a product becomes, the scarcer it becomes in the market"(2000: 425). Marsden et al. (2000), and later Renting et al. (2003), identify three main types of SFSC, all of which engender some form of 'connection' between the food consumer and producer.

Face-to-face: consumer purchases a product direct from the producer/processor on a face-to-face basis. Authenticity and trust are mediated through personal interaction

Spatial proximity: products are produced and retailed in specific region of production, and consumers are made aware of the 'local' nature of the product at the point of sale. This category overlaps with the 'face-to-face' category and includes the same retail spaces as noted above. In addition, this category could include specialist retailers (e. g. delicatessens, bakeries, butchers, grocers) which sell 'local' produce and also elements of the hospitality industry which sell local foods (e. g. restaurants, pubs, hotels and other accommodation). This category could also include public sector food provision, such as hospitals, schools, universities, care homes, prisons and so on which either sell or provide locally sourced foods.

Spatially extended: information about the place and processes of production is communicated to consumers who are outside of the region of production itself, and who may have no personal experience of that region. All types of retail space 
are potentially appropriate for this type of SFSC. The product information is communicated through product packaging and promotion, branding, and the use

of certification and legislation to protect named products with distinct geographical origin. This legally forced system sidesteps the whole problem of defining 'the local' itself, by insisting instead that the crucial point of definition is whether a food product's characteristics are attributable wholly or in part to the features of a distinct - and usually relatively small geographical area.

Important economic factors of producers' interaction with marketing and food supply chain Broderick et al. highlight are:

- Labour family labour, volunteer labour, apprentice labour,

casual labour, professional labour and fees

- Marketing margin

- Negotiation costs

- Transaction costs

Maxey et al. (2011) have examined the economics of growing food on small-scale sites with 10 acres (4 ha) or less. They use eight current UK case studies: four fruit and vegetable growers, a mushroom grower, a ducklings hatchery, a mail order seed company, and a mixed holding selling cider, honey,eggs, and lamb. The threshold of 4 ha is below the level at which farms are typically considered viable in the UK; e. g. 5 ha (12 acres) are required for a farm to qualify for permitted development rights. The authors conclude that economically viable and sustainable land based enterprises can be created on holdings of 4 ha or less. In addition small livelihoods can be created on marginal sites, as illustrated by some of the case studies. These livelihoods often follow a slow development trajectory, allowing growers to avoid commercial loans and time to develop "in harmony with the ecosystem" as the authors put it.

To judge the ecological or economic success of these smallholdings it is recommended to take a long term view. The mental attitude and approach are seen as the most significant factor in creating viable smallholdings. This approach includes commitment, willingness to work long hours, patience, long-term perspective and creative, solution focused thinking. All eight case studies achieve high yields per unit area by intensive and/or diverse cropping and then add value through processing and direct marketing.

Enterprise diversity is a common feature of the successful case studies. The most profitable small-scale land based enterprises are labour intensive and horticulture is seen as better suited to small scale than livestock. Where smallholders can purchase land at agricultural land prices, the system offers affordable opportunities to enter farming. These case study success stories reported from various countries contrast somewhat with findings when a large survey is conducted.

\section{Methodology}

The main objective of this paper is to understand the farmers attitudes towards the direct sale and their willing to participate to local supply chain. In this study is used the quantitative methods approach through the use of surveys to collect data. The survey was conducted between October 2015 and November 2015 with 150 Albanian farmers from different districts.

\section{Results}

The survey was orientated to three main issues :

difficulties that farmers face to sell their production

general interest to local products. 
reasons that may lead to local products

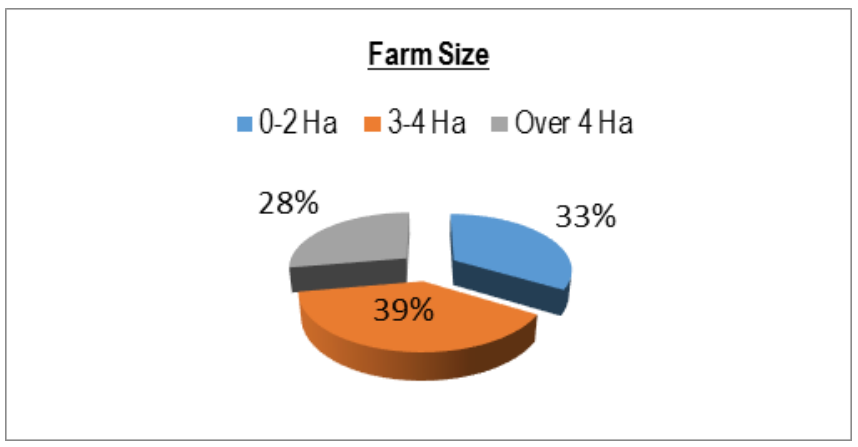

Fig. 1

The farmers willing to participate to direct sales.

The farmes are asked if extension servise, advise them about marketing and how they can sell their production. The following results show that major part respondents are not advised for the alternatives of facing the market.

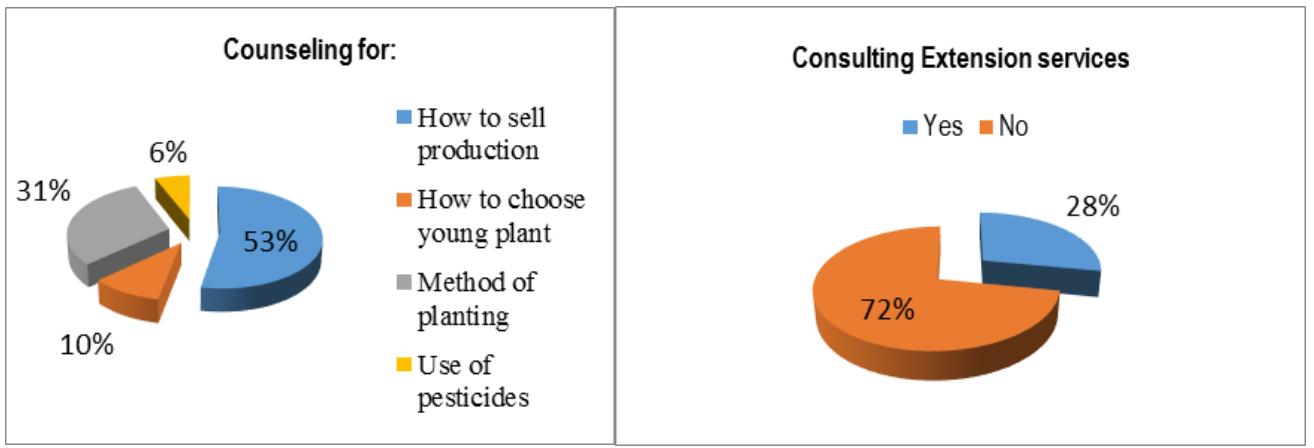

Fig. 2

Fig. 3

Regarding the general interest of local products, there is ambiguity in the term "local" among participants who perceive it as such in general domestic production, it also due to the fact that Albania is a small country and physical distances are relatively remote. What can be said without hesitation is a revival of interest in local products. Reasons vary among farmers but all perceive that local production have many advantages comparing to import products. They perceive a tough competition from imported products. 


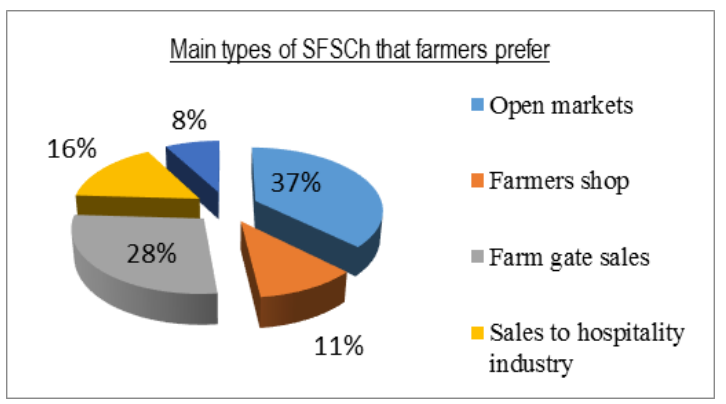

Fig. 5

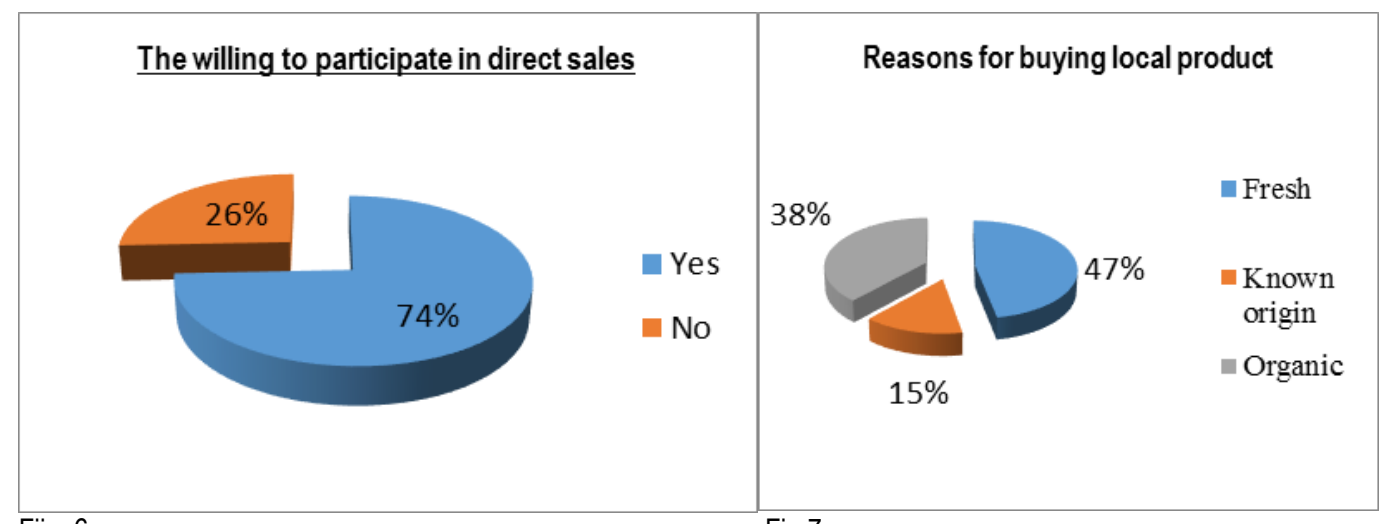

Fiig. 6

Fig 7

As it's seen the most preferred direct sales are open market, farm gate sales and hospitality industry (fig. 5). Farmers argue these responses as below:

Advantages of "open market" :

Direct contact with costumer

Direct contact builds up trust between farmers and costumers

Interaction in the process of purchase and sale.

Advantages of "farm gate sales":

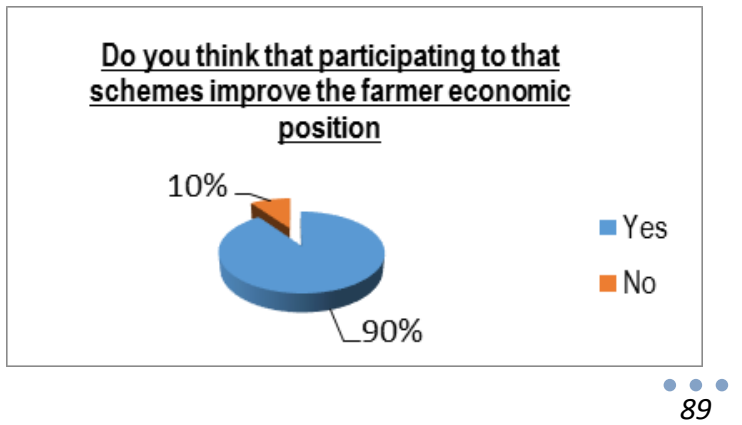


Reduction of transportation cost

Reduction of time waste for farmers

Trust of direct contact

Advantages of "sales to hospitality industry":

Oportunity to sell all production Reasonable prices

Builds trust

The major part of farmers think that if they would participate to these forms of direct sales, they could improve their economic position and would be more competitive (fig. 6).

\section{Conclusion}

The Albanian agriculture based on the small family farm, is a crossing to find its way of development as one of the most important sectors of economy. This new tendency that has been appeared to the albanian consumer is one of the possibilities for the small farms for which is almost impossible to be efficient in the intensive agriculture. They find it impossible to be part of the modern food supply chains. But these farms can be focused on the added valued product, reffering to the traditional methods of the production and the food supply short chains.

Our findings undoubtedly require further analysis and contextualization in a wider scenario. However, results show a strong willing of farmers to be part of direct sales, although local has become the new mantra (duPuis and Goodman, 2005), practical and socio-cultural dimensions still direct shoppers' choices, raising interesting questions on the role of alternative food networks.

Limitations of the current work are related to the explored sample is limited in terms of number respondents, which are not statistically representative of the albanian population. Another quantitative analyse would have given the final results more general significance.

\section{Bibliography}

Broderick, S., Wright, V., and Kristiansen, P. (2011)'Cross-Case Analysis of Producer-Driven Marketing Channels in Australia. British Food Journal 113 (10), 1217-1228.

Du Puis, M. d. (2005): " Should we go ' home' to eat?: Toward a reflective politics of localism". Journal of Rural Studies, 359-371.

Marsden, T. (2000): " Food Matters and Matters of Food: Towards a New Food Governance". Sociologia Ruralis, 20-29.

Marsden, T.,Banks, J. and Bristow, G.. (2000): " Food supply chain approaches: exploring their role in rural developement". Sociologia Ruralis, 424-438.

Maxey, L., Laughton, R., Rodker, O., and Wangler, Z. (2011) Small is Successful! Creating Sustainable Livelihoods on Ten Acres or Less [online] available from www. ecologicalland. coop London: The Ecological Land Co-operative Ltd.

Renting,H., Marsden,T. (2003): " Understanding alternative food networks: Exploring the role of short food supply chains in rural development". Environment and Planning,Vol. 35, 393-411. 